\title{
Biology, Reproductive Capacity, and Foliar Consumption of Diabrotica speciosa (Germar) (Coleoptera: Chrysomelidae) in Different Host Plants
}

\author{
Crébio José Ávila ${ }^{1}$, Darque Ratier Bitencourt ${ }^{2} \&$ Ivana Fernandes da Silva ${ }^{2}$ \\ ${ }^{1}$ Departamento de Entomologia, Empresa Brasileira de Pesquisa Agropecuária Oeste, Dourados, Brazil \\ ${ }^{2}$ Departamento de Entomologia e Conservação da Biodiversidade, Universidade Federal da Grande Dourados, \\ Dourados, Brazil \\ Correspondence: Ivana Fernandes da Silva, Departamento de Entomologia e Conservação da Biodiversidade, \\ Universidade Federal da Grande Dourados, Dourados, Brazil. E-mail: ivanaf.silva@hotmail.com
}

$\begin{array}{ll}\text { Received: December 10, } 2018 & \text { Accepted: February 9, } 2019 \quad \text { Online Published: April 15, } 2019 \\ \text { doi:10.5539/jas.v11n5p353 } & \text { URL: https://doi.org/10.5539/jas.v11n5p353 }\end{array}$

\begin{abstract}
Diabrotica speciosa is considered one of the most important agricultural pests in Latin America. Attacks various plant species including fructiferous, vegetable, cucurbit, dicotyledonous, and gramineous crops. The goal of this work was to evaluate the influence of different host plants, offered during the larval and adult stages of $D$. speciosa on their development, reproductive capacity, and foliar consumption. The insects were reared with corn in the larval stage and offered common bean, corn, soybean, forage turnip and wheat in the adult phase. In another essay, the larvae were reared with bean, soybean, forage turnip, corn, wheat, potato and adult stage offered only leaves of common beans to the insects. The insects reared with corn and fed on common bean leaves in the adult phase produced bigger numbers of eggs in contrast to the insects fed on other host plants. The longevity of adult specimens and the oviposition period were greater when adults of D. speciosa were fed on soybean, forage turnip, and common bean leaves, but these parameters were reduced in the insects fed on corn and wheat leaves. The viability of $D$. speciosa during the immature stage was greater when the larvae were fed with potato tubers or corn seedlings. However, the larvae reared on potato tubers exhibited a longer development period in contrast to larvae fed on other plants. In the foliar consumption tests, common bean leaves were preferred by adult of $D$. speciosa in contrast to other plants (soybean, corn and forage turnip) offered under free-choice conditions. On the other hand, in confinement conditions, common bean was preferred by insects when compared to turnip or corn leaves. The results showed that corn was the best food for the larval development of $D$. speciosa while common bean represented the most suitable host for the adults.
\end{abstract}

Keywords: corn rootworm, plant host, polyphagous insect, insect development

\section{Introduction}

Diabrotica speciosa (Germar, 1824) (Coleoptera: Chrysomelidae) is a polyphagous insect that attacks various plant species and can cause economic damage depending on the populational level (Ventura et al., 2001; Oliveira \& Ramos, 2012; Cabrera, Walsh, \& Cabrera, 2016). This pest is considered one of the most important agricultural pests in Latin America (Ávila \& Santana, 2013; Cabrera Walsh, \& Cabrera, 2016; Marchioro \& Krechemer, 2018). It has been shown by some authors that larvae and adults of $D$. speciosa have different food preferences (Lara et al., 2001; Ávila \& Parra, 2002; Garcia et al., 2014; Boiça Júnior et al., 2015; Costa et al., 2018). The larvae are whitish and have their head and anal plate darkened (Pecchioni et al., 2000). Live in the soil where feed the underground parts of plants (Ávila \& Milanez, 2004; Santos et al., 2014). The adults are green beetles with three yellow spots on each wing and the reddish head. Live on the aerial parts of plants, feeding on leaves, shoots, pods and fruits of different species plants (Ávila \& Milanez, 2004; Eben \& Monteros, 2013). In locations where populations of $D$. speciosa are established, more than one plant species may be available in adjacent areas, whereas in other areas, the insect has only one host species. There is little information regarding some biological aspects, such as adult longevity, consumption capacity, and fecundity in D. speciosa when fed on different host plants in the larval and/or adult stage (Milanez \& Parra, 2000; Teodoro et al., 2014). 
Nutritional quality, as well as the phenological age of the host available during the larval and adult stages of $D$. speciosa can interfere in its biology and reproductive capacity and, consequently, in the potential damage caused to crops (Panizzi \& Parra, 2009; Ávila \& Parra, 2003; Cohen, 2015). Wherefore, studies of this nature may assist in the understanding of factors that determine the population dynamics of insects in crop systems, thus contributing to the enhancement and development of management strategies. Furthermore, such information could contribute to the maintenance of colonies of insects under laboratory conditions, which is essential for basic and applied research because to the fact that they require a large and steady supply of insects (Parra, 2001). Knowledge, the oviposition capacity of D. speciosa can be influenced by the nutritional quality of the food consumed during the larval or adult stages (Ávila \& Parra, 2002). Many ecological, physiological, and behavioral processes exhibited by the insects are related to the nutritional context (Cohen, 2015). Thus, it is extremely important to know the behavior, food preference, dietary habits, and nutritional needs of these insects and their consequences on growth, survival, longevity, and reproduction (Panizzi \& Parra, 2009; Ávila \& Parra, 2003). The objective of this paper was to evaluate the influence of different host plants offered during the larval and adult stages of $D$. speciosa on their development, reproductive capacity, and foliar consumption.

\section{Materials and Methods}

Bioassays were conducted in Embrapa Agropecuária Oeste $\left(22^{\circ} 13^{\prime} 16^{\prime \prime} \mathrm{S}, 54^{\circ} 48^{\prime} 20^{\prime \prime} \mathrm{W}\right.$, at $430 \mathrm{~m}$ altitude) the county of Dourados, State of Mato Grosso do Sul, Brazil. D. speciosa was reared in the laboratory, aiming at obtaining larval and adult specimens to be used in this study.

Wild adult insects used to initiate mass-rearing were collected in Dourados county, Mato Grosso do Sul State. Insect collections were held periodically in the common bean field for maintenance of the rearing procedures. The adult specimens were fed on common bean leaves (Phaseolus vulgaris L.) and the larvae were reared on corn seedlings (Zea mays L.), according to the method proposed by Ávila \& Santana (2013). The insects were kept in an acclimatized room $\left(25 \pm 2{ }^{\circ} \mathrm{C}, \mathrm{RH}=60 \pm 10 \%\right.$, and 14-hour photophase), and a change of adult food was performed every 48 hours. Petri dishes $(90 \times 15 \mathrm{~mm})$ containing filter paper moistened with water and black gauze were used as an oviposition substrate in the rearing cages. Every two days, the gauze with eggs were washed in running distilled water over voile fabric where the eggs were retained. To avoid contamination by fungi during the incubation period, eggs were treated with $1 \%$ copper sulfate $\left(\mathrm{CuSO}_{4}\right)$ solution for 30 seconds and kept under conditions of temperature controlled conditions until larval hatching.

All of the adult insects used in this bioassay were from rearing in which the larvae were fed on corn seedlings (Figure 1A). The adult were separated by sex according to the sexual dimorphism characteristics described by De Carli (2018) and the couples were individualized in cages made of transparent acrylic jars $(13 \mathrm{~cm}$ long $\times 8$ $\mathrm{cm}$ base) inverted on Petri dish. There was a pot of glass with water in these cages, in which the petioles of the leaves of the host plant were submerged for feeding the adult insects. The base of the jar $(50 \mathrm{~mL})$ was drilled and coated with voile fabric to allow the entry of air in the cage. A circular-shaped container with black gauze moistened in water was placed at the bottom of each Petri dish where females laid their eggs. The adult insects were fed on leaves of common bean, soybean, forage turnip, corn, or wheat throughout the oviposition period, and ten couples of $D$. speciosa were used in each treatment.

The biological parameters assessed were the number of eggs found in the cage every four days, the incubation period and egg viability, pre-oviposition and oviposition periods, fecundity, and the longevity of males and females. The experiments was carried out using the entirely casualized design with five treatments (host plants) (Figure 1A) and ten repetitions. The data on the biological parameters were subjected to variance analysis. When verified significant effect of treatment, confirmed through the F-test, the treatments were compared using Tukey's test at the 5\% probability level. The data of the fecundity were transformed using the square root transformation $(\mathrm{x}+0.5)$, and the percentage of egg viability was subjected to arcosene transformation $(\mathrm{x} / 100)$. Larvae of $D$. speciosa were fed on seedlings of common bean, soybean, forage turnip, corn, wheat, and potato tuber, until they reached the pupal stage (Figure 1B). All of the insects used in the bioassay were obtained from $D$. speciosa reared in the laboratory, according to the method described in section "rearing of D. speciosa". The different plants were used as larval food, and in the adult phase common bean leaflets were used in all treatments. To the production of food to the larval phase, seeds or tubers were put to germinate in plastic trays containing vermiculite sterilized and kept in greenhouse. The seedlings or tubers were kept in sterilezed moist vermiculite in a ratio of 1.6 parts water to 1 part of vermiculite (1.6: 1$)$ in grams. 
A
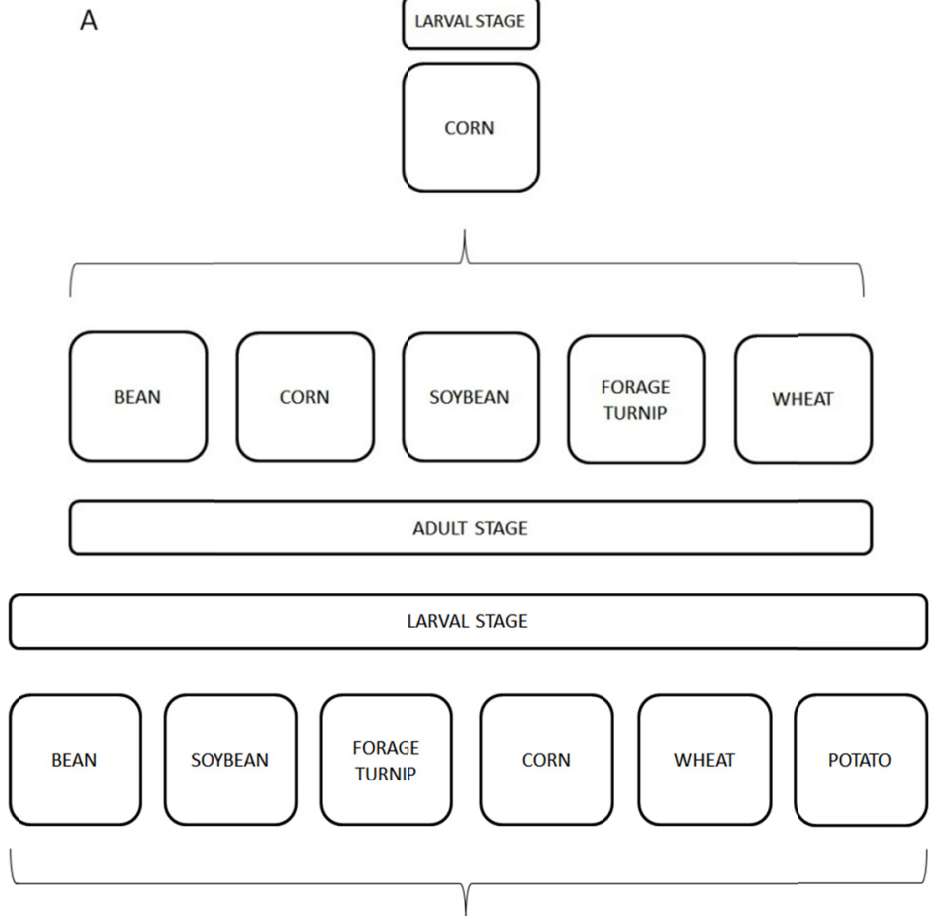

BEAN

$B$

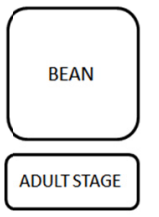

Figure 1. Graphical representation of the bioassays conducted to assess the influence of host plants as food during the adult stage (A) and the larval stage (B) of D. speciosa

Fifty newly hatched larvae (up to 24 hours old) of $D$. speciosa were transferred to rearing pots containing seedlings or tubers of the different hosts, using the proportion of one larva for each seedling or potato tuber. The adults that emerged from each rearing system were separated by sex and the couples were individualized in cages containing common bean seedlings, as described in previous section. The biological parameters assessed were the viability of immature stages (larva to adult), pre-oviposition and oviposition periods, fecundity and longevity of adults ( $\hat{O}$ and $q$ ), and the incubation period and viability of eggs.

The experiments were conducted in the entirely casualized design with six treatments (host plants) (Figure 1B) and ten repetitions. The data on the biological parameters were subjected to variance analysis. When was verified significant effect of treatment through the F-test, the treatments were compared using Tukey's test at the 5\% probability level. The data of the fecundity were transformed using the square root transformation $(\mathrm{x}+0.5)$, whereas the percentage of egg viability was subjected to arcosene transformation $(\mathrm{x} / 100)$.

Adults from the mass-rearing of $D$. speciosa in corn seedlings were used to assess foliar consumption. In order to reduce the imaginal preconditioning of insects reared on corn, the newly emerged adults under these conditions were kept for 24 hours, feeding on potato leaflets, once corn was used as treatment in adult phase. The foliar consumption of adults was assessed in plants of common bean, soybean, corn, and forage turnip with, approximately, 22 days after emergence. For the assessment of foliar consumption, the adults of $D$. speciosa were confined in Petri dishes $(14 \times 2 \mathrm{~cm})$ and they were offered foliar disks of different host plants measuring $2.8 \mathrm{~cm}$ in diameter, under free-choice and confinement conditions. The Petri dishes contained plaster on the bottom for fixing the leaf discs covered with filter paper moistened in water.

In the tests under free-choice conditions, one foliar disks $(2.8 \mathrm{~cm}$ in diameter) of the four host plants were offered in the form of an arena for two couples of $D$. speciosa during 24 hours, as described by Ávila \& Parra (2003). After this feeding period, the adults were removed from the Petri dish and the foliar area remaining in the disks was determined by calculating the difference between the initial area of the foliar disk provided to the 
insects and the foliar area remaining after the feeding period. To calculate the remaining area of leaf disks we used a leaf area meter LI-COR ${ }^{\circledR}$, model 3100 .

In the test without choice options (confinement), two foliar disks $(2.2 \mathrm{~cm}$ in diameter) of each host plant were offered separately. Each treatment had ten repetitions, and the experiment was conducted in a completely randomized design.

The data of the foliar consumption were subjected to variance analysis. When was verified significant effect of treatment through the F-test, the treatments were compared using Tukey's test at the 5\% probability level.

\section{Results}

\subsection{Fecundity and Longevity of D. speciosa Fed on Different Host Plants During the Adult Stage}

A greater number of eggs of D. speciosa (F) were observed in the treatment in which the adults were fed on common bean plants (Table 1). Soybean and turnip plants provided intermediate production of eggs by females. However, regarding the insects fed on wheat, egg production was drastically reduced, whereas there was no ovipositionfor the insects fed on corn plants. The pre-oviposition period (PP) of D. speciosa was greater for insects fed on forage turnip, followed by soybean and common bean and lower with wheat (Table 1), whereas with corn was not observed laying. When wheat plants were used as food, the oviposition period (OP) lasted only four days, while with common bean, soybean and turnip was observed on average from 35.8 to 41.3 days, without a significant difference between these last one.

Table 1. Pre-oviposition period (POP), oviposition period (OP) and fecundity (F) of D. speciosa when reared on corn during the larval stage and fed on different host plants on the adult stage

\begin{tabular}{llll}
\hline Host plant & PP (days) & OP (days) & F $\left(\mathrm{N}^{\circ}\right.$ of eggs $)$ \\
\hline Common bean & $9.7 \pm 1.1 \mathrm{ab}$ & $41.3 \pm 6.3 \mathrm{a}$ & $746.6 \pm 161.9 \mathrm{a}$ \\
Soybean & $7.6 \pm 1.3 \mathrm{ab}$ & $40.8 \pm 6.7 \mathrm{a}$ & $323.9 \pm 66.1 \mathrm{~b}$ \\
Turnip & $12.8 \pm 2.2 \mathrm{a}$ & $35.8 \pm 5.9 \mathrm{a}$ & $225.8 \pm 51.8 \mathrm{~b}$ \\
Corn & -1 & -1 & $0.0 \pm 0.0 \mathrm{c}$ \\
Wheat & $7.2 \pm 0.9 \mathrm{~b}$ & $4.0 \pm 3.7 \mathrm{~b}$ & $2.8 \pm 0.6 \mathrm{c}$ \\
\hline CV $(\%)$ & 23.2 & 29.3 & 75.2 \\
\hline
\end{tabular}

Note. ${ }^{1}$ Oviposition was not observed.

Averages followed by the same letter did not differ significantly between them according to Tukey's test $(p<$ $0.05)$.

Regarding adult longevity, it was observed that male and female of $D$. speciosa fed on common bean, soybean, and forage turnip were significantly more longevous ( $>44$ days) than adults fed on corn or wheat considering both sexes (Table 2). No differences were found for incubation period (PI) and the viability of the eggs (VO) by the adults fed on common bean, soybean, or turnip (Table 2). Since oviposition of females fed on wheat was very low and absent when fed on corn, it was not possible to assess the viability of the eggs of D. speciosa in these two hosts.

Table 2. Longevity of male and female, incubation period (IP) and viability (V) of eggs of D. speciosa when reared on corn during the larval stage and fed on different host plants on the adult stage

\begin{tabular}{|c|c|c|c|c|}
\hline \multirow{2}{*}{ Host plant } & \multicolumn{2}{|c|}{ Longevity (days) } & \multirow{2}{*}{ IP (days) } & \multirow{2}{*}{ V $(\%)$} \\
\hline & $\hat{0}$ & q & & \\
\hline Common bean & $48.4 \pm 5.0 \mathrm{a}$ & $56.1 \pm 7.3 \mathrm{a}$ & $9.6 \pm 0.70 \mathrm{a}$ & $26.0 \pm 2.75 \mathrm{a}$ \\
\hline Soybean & $44.6 \pm 5.5 \mathrm{a}$ & $55.0 \pm 6.3 \mathrm{a}$ & $8.6 \pm 1.39 \mathrm{a}$ & $24.0 \pm 4.64 \mathrm{a}$ \\
\hline Turnip & $45.9 \pm 7.3 \mathrm{a}$ & $57.0 \pm 8.2 \mathrm{a}$ & $7.6 \pm 1.23 \mathrm{a}$ & $30.0 \pm 5.28 \mathrm{a}$ \\
\hline Corn & $14.3 \pm 2.2 \mathrm{~b}$ & $16.8 \pm 1.3 \mathrm{~b}$ & -1 & - \\
\hline Wheat & $15.4 \pm 2.0 \mathrm{~b}$ & $16.6 \pm 2.0 \mathrm{~b}$ & -2 & - \\
\hline $\mathrm{CV}(\%)$ & 26.2 & 23.4 & 16.3 & 26.3 \\
\hline
\end{tabular}

Note. ${ }^{1}$ Oviposition was not observed; ${ }^{2}$ Insufficient number of eggs to assess incubation and viability.

Averages followed by the same letter did not differ significantly between them according to Tukey's test ( $p<$ $0.05)$. 


\subsection{Fecundity and Longevity of D. speciosa Fed on Different Host Plants During the Larval Stage}

The pre-oviposition period (PP) was greater for D. speciosa reared on soybean in contrast to the period of those fed on common bean, corn, or potato (Table 3). Intermediate values were observed to the insects feed on forage turnip or wheat during the larval stage. The oviposition period (OP) was shorter for insects reared on forage turnip in contrast to the period of those fed on common bean. Fecundity (F) was significantly higher to the insects reared with corn during the larval stage, which surpassed all other host plants, and it was shorter in those reared on forage turnip, although it did not differ from the values observed to the insects reared on potato and wheat.

Table 3. Pre-oviposition period (PP), oviposition period (OP), fecundity (F), and longevity of D. speciosa when reared on different host plants during the larval stage and fed with common bean on the adult stage

\begin{tabular}{llllll}
\hline \multirow{2}{*}{ Host plant } & PP (days) & OP (days) & F (No of eggs) & \multicolumn{2}{c}{ Longevity (days) } \\
\cline { 5 - 6 } & & & & \multicolumn{2}{c}{ (d) } \\
\hline Common bean & $8.8 \pm 0.52 \mathrm{~b}$ & $45.2 \pm 9.4 \mathrm{a}$ & $285.5 \pm 97.2 \mathrm{~b}$ & $53.8 \pm 12.3 \mathrm{ab}$ & $62.0 \pm 9.0 \mathrm{a}$ \\
Soybean & $15.2 \pm 1.79 \mathrm{a}$ & $37.6 \pm 7.1 \mathrm{ab}$ & $236.6 \pm 73.0 \mathrm{~b}$ & $62.3 \pm 10.3 \mathrm{a}$ & $63.3 \pm 8.5 \mathrm{a}$ \\
Turnip & $16.0 \pm 2.53 \mathrm{ab}$ & $27.33 \pm 8.9 \mathrm{~b}$ & $36.7 \pm 31.9 \mathrm{c}$ & $38.7 \pm 7.7 \mathrm{ab}$ & $39.4 \pm 6.9 \mathrm{a}$ \\
Potato & $12.0 \pm 1.90 \mathrm{~b}$ & $32.57 \pm 10.7 \mathrm{ab}$ & $125.4 \pm 49.4 \mathrm{bc}$ & $21.6 \pm 7.1 \mathrm{~b}$ & $44.2 \pm 9.9 \mathrm{a}$ \\
Corn & $9.7 \pm 1.08 \mathrm{~b}$ & $41.3 \pm 6.3 \mathrm{ab}$ & $746.6 \pm 16.9 \mathrm{a}$ & $48.4 \pm 5.0 \mathrm{~b}$ & $56.1 \pm 7.3 \mathrm{a}$ \\
Wheat & $14.0 \pm 2.24 \mathrm{ab}$ & $29.6 \pm 2.9 \mathrm{ab}$ & $143.4 \pm 30.8 \mathrm{bc}$ & $46.1 \pm 7.7 \mathrm{ab}$ & $51.0 \pm 5.9 \mathrm{a}$ \\
CV $(\%)$ & 33.4 & 66.9 & 70.8 & 36.2 & 27.6
\end{tabular}

Note. Averages followed by the same letter did not differ significantly between them according to Tukey's test ( $p$ $<0.05)$.

There were no differences regarding female longevity when reared on different host plants during the larval stage. However, male longevity was longer in the insects fed on soybean during the larval stage and shorter in those fed on potato and corn, and with intermediate values observed in those fed on other host plants (Table 3). The greatest viability during the immature stage (VLA) was observed when the larvae were reared on corn seedlings, followed by potato tubers, and lower when fed with other host plants (Table 4). The larval-adult period (D) was higher for tha insects reared in potato tubers in relation others host plants. The incubation period of eggs (PI) from insects reared on corn seedlings was greater in relation to the other host plants use as food (Table 4). The viability of eggs (VO) from insects reared on wheat was greater than the insects reared on common bean during the larval stage without, however, differing from the other treatments (Table 4).

Table 4. Incubation period (IP), viability of eggs (V), duration (D) and viability the larval-adult period (VLA) de D. speciosa when reared on different host plants during the larval stage and fed with common bean on the adult stage

\begin{tabular}{lllll}
\hline Host plant & IP (days) & V $(\%)$ & D (days) & VLA (\%) \\
\hline Common bean & $6.2 \pm 0.3 \mathrm{bc}$ & $21.0 \pm 1.8 \mathrm{~b}$ & $26.0 \pm 0.3 \mathrm{bc}$ & $7.9 \pm 0.7 \mathrm{c}$ \\
Soybean & $7.2 \pm 1.2 \mathrm{~b}$ & $24.0 \pm 4.0 \mathrm{ab}$ & $25.6 \pm 0.4 \mathrm{bc}$ & $11.0 \pm 0.9 \mathrm{c}$ \\
Turnip & $6.2 \pm 1.1 \mathrm{bc}$ & $26.0 \pm 4.6 \mathrm{ab}$ & $24.9 \pm 0.4 \mathrm{c}$ & $4.6 \pm 0.4 \mathrm{~d}$ \\
Potato & $7.2 \pm 1.2 \mathrm{~b}$ & $25.0 \pm 4.4 \mathrm{ab}$ & $31.5 \pm 0.9 \mathrm{a}$ & $24.2 \pm 3.4 \mathrm{ab}$ \\
Corn & $9.6 \pm 0.7 \mathrm{a}$ & $26.0 \pm 2.7 \mathrm{ab}$ & $25.1 \pm 0.2 \mathrm{c}$ & $31.0 \pm 3.7 \mathrm{a}$ \\
Wheat & $5.6 \pm 0.9 \mathrm{c}$ & $29.0 \pm 5.1 \mathrm{a}$ & $28.0 \pm 1.7 \mathrm{~b}$ & $17.7 \pm 2.7 \mathrm{~b}$ \\
\hline CV $(\%)$ & 15.8 & 19.0 & 6.2 & 16.9
\end{tabular}

Note. Averages followed by the same letter did not differ significantly between them according to Tukey's test ( $p$ $<0.05)$.

\subsection{Foliar Consumption of Adult Specimens of D. speciosa in Different Host Plants}

Adults of $D$. speciosa preferred feed on common bean leaves rather than soybean, forage turnip, and corn under free-choice conditions (Table 5). Under confinement conditions, the leaves of forage turnip and corn were less 
consumed by the insects when compared to common bean leaves, with an intermediate value for the consumption of soybean leaves.

Table 5. Foliar area of common bean, soybean, turnip, and corn consumed by adults of D. speciosa for 24 hours in free-choice and confinement tests

\begin{tabular}{lll}
\hline Host plant & Free-choice & Confinement \\
\hline Common bean & $20.65 \pm 0.3 \mathrm{a}$ & $8.99 \pm 0.6 \mathrm{a}$ \\
Soybean & $19.26 \pm 0.1 \mathrm{~b}$ & $7.84 \pm 0.2 \mathrm{ab}$ \\
Turnip & $19.47 \pm 0.2 \mathrm{~b}$ & $7.73 \pm 0.2 \mathrm{~b}$ \\
Corn & $19.39 \pm 0.1 \mathrm{~b}$ & $7.59 \pm 0.1 \mathrm{~b}$ \\
\hline CV $(\%)$ & 3.33 & 12.58 \\
\hline
\end{tabular}

Note. Averages followed by the same letter did not differ significantly between them according to Tukey's test ( $\mathrm{p}$ $<0.05)$.

\section{Discussion}

The results have shown evidence that the food needs of $D$. speciosa are different for the larval and adult stages. In general, the adults had better development and preference to the bean plant, while the larvae showed better development on the maize seedlings. Furthermore, the stages immature and adult of $D$. speciosa do not compete for space or nutritional resources since the larvae feed on the roots and adults feed on the leaves of the plants (Garcia et al., 2014). However, the adults survived and reproduced when fed with soybean (Costa et al., 2014) and turnip during the adult stage, similarly completed their development and reproduction even when fed on alternative hosts in the larval stage with beans, soybeans, turnip, potato and wheat. These results corroborate with that observed by Branson and Krysan (1981) who argued that even species of the genus Diabrotica considered monophagous, or with narrow range of host plants can complete its life cycle in the absence of a preferencial host and consequently ensure their survival in the field.

The insects fed on common bean leaves produced greater numbers of eggs in contrast to the insects fed on other host plants during the adult stage. Ávila and Parra (2002) also found that common bean and potato leaves provided greater fecundity to D. speciosa when the insects were fed on these plants during the adult stage, in contrast to the fecundity provided by soybean or corn leaves. The same authors found through foliar analysis, that the foliar nitrogen concentration is apparently lower in corn and higher in potato and they concluded that the oviposition capacity of $D$. speciosa may be related to the differences in the amount of nitrogen found in the leaves these host plants. From knowledge, the development, survival, rhythm of oviposition, fecundity and fertility of $D$. speciosa are influenced negatively by maize varieties, possibly the existence of any morphological barriers in the roots of these plants is already possible the correlation with the resistance of plants to the larval attack of the species (Costa et al., 2018). Another study showed that adults of D. speciosa when fed with bean leaves, carrot and honey (10\%) has higher fecundity and net reproductive rate compared to those adults that fed only of bean leaves (Teodoro et al., 2014). More, Garcia et al. (2014) argued that the corn when intercropped with other plants, such as potatoes, soybeans and beans, can affect the spread of adults of D. speciosa in the field, functioning as a natural barrier to this pest, providing population reduction through the insertion corn lines near the starting point of invasion of the pest in the field, acting as the control strategy.

The longevity of adult and the oviposition period were greater when the adult of $D$. speciosa were fed in the larval stage with soybean, forage turnip, and common bean leaves. These parameters were reduced in the insects fed on corn and wheat. According to Panizzi and Parra (2009), the main function of the adults is related to reproduction and dispersal. These functions are dependent of the interaction between physiological and behavioral processes, which are closely correlated to the consumption and use of food. Biological aspects such as fertility and viability of eggs on insects may be influenced by the type of food ingested, because different species of plants have different secondary compounds and concentrations of nutrients that can impact positively or negatively on the development of insects (Panizzi \& Parra, 2009). In addition, Awmack and Leather (2002) stressed that the quality of host plants components, such as carbon, nitrogen, and secondary defense metabolites, directly affect the fecundity of herbivorous insects. Naranjo and Sawyer (1987) also found that the fecundity and longevity of Diabrotica barberi (Smith \& Lawrence, 1967) (Coleoptera: Chrysomelidae) were significantly affected by the type of food used during the adult stage. Generally, insects that fed on fresh material produced an increased number of eggs in the oviposition period and the longevity of females was increased in contrast to 
insects that fed on less fresh food. The presence of fresh food, especially that of a larval host, greatly stimulates oviposition (Costa et al., 2014). The same study also found that insects (male and female) which received only water or corn leaves were less longevous, similar to that observed in this paper.

The viability of $D$. speciosa during the immature stage was greater when the larvae fed on potato tubers or corn seedlings. However, the larvae reared on potato tubers exhibited a longer development period in contrast to larvae fed on other plants assessed. Ávila and Parra (2002) found that potato tubers and corn seedlings provided greater larval viability of $D$. speciosa in contrast to soybean and common bean seedlings. Cabrera Walsh (2003) also found that the larvae of $D$. speciosa reared on corn seedlings exhibited greater viability in contrast to those reared on squash, wheat, peanut, soybean, common bean, or potato tuber. Still, this author observed that the period of $D$. speciosa development (egg to adult) reared on potato tuber and common bean or soybean seedlings was longer than the development period observed in insects reared with pumpkin, peanut, wheat, or corn. However, although D. speciosa in the larval stage have shown better development in corn, other plants also allowed the insect development. These results demonstrate that in the absence of a preferential host plant to the larvae, the insect can use soybean, beans, turnip, wheat and potatoes as food to complete the its development and reproduction. Ávila and Parra (2002) also found that soybean and beans serve as alternative hosts for the larvae of D. speciosa.

In the foliar consumption tests, common bean leaves were preferred by adult of $D$. speciosa in contrast to other plants offered under free-choice conditions. On the other hand, in confinement, the insects fed on other plants, but common bean was preferred again only in relation to forage turnip or corn. Similar results were found by Ávila and Parra (2003) who observed that common bean leaves were more consumed by adult of D. speciosa in contrast to those fed on potato, soybean, and corn under free-choice conditions. However, these authors observed that in confinement there was greater consumption of potato than corn, with intermediate values observed for common bean and soybean. Marques et al. (1999) also observed that the consumption of soybean and common bean leaves by adults of $D$. speciosa was greater than the consumption of corn or rice leaves.

This host selection by insects for different plant species is often associated with the perception of volatile compounds emitted by host plants through olfactory sensilla present in the body of insects. According to Pereira et al. (2005), the larvae of D. speciosa are attracted by $\mathrm{CO}_{2}$ emitted by the roots of plants. Furthermore, plants emit volatile substances that can be identified by insects and influence the search behavior of the larvae for food. In the same study, the authors found that popcorn, corn, and oat plants are more attractive to insects than sorghum plants. Today it is known that differents plant volatiles may cause behavioral responses in larvae of the genus of Diabrotica (Rasmann et al., 2005; Johnson \& Gregory, 2006; Rasmann \& Turlings, 2008). According to Johnson and Gregory (2006) soil pests are deprived of visual cues and are guided primarily by the chemical clues to find your host.

The corn was the most appropriate plant for the larval development of D. speciosa, because it provided greater fecundity in insects reared on this host and fed on common bean during the adult stage. Milanez (1995) showed that females of $D$. speciosa prefer lay their eggs closer to corn plants, although they can select other plants for food. In addition, this author observed that the immatures of $D$. speciosa have better performance when fed with corn roots that provide higher survival and weight gain. Ventura and Gomes (2004) evaluating the population of larvae of D. speciosa in fields with corn, wheat or oat, observed that the highest peak of larvae was verified in corn. Krysar (1981) argues that corn is a preferential host plant of D. speciosa due the relations of co-evolution of the insects and plants. On the other hand, common bean plants were the most appropriate host during the adult stage. Corn used during the larval stage and common bean during the adult stage represented the most appropriate food for insect development in contrast to the other hosts tested. These results explain why $D$. speciosa, in the immature and adult stages is an important pest of corn and common bean plants, respectively.

\section{References}

Ávila, C. J., \& Milanez, J. M. (2004). Larva alfinete. In J. R. Salvadori, C. J. Ávila, \& M. T. B. Silva (Eds.), Pragas de solo no Brasil (pp. 345-378). Embrapa Trigo, Embrapa Agropecuária Oeste e Cruz Alta, Fecotrigo, Passo Fundo, Brazil.

Ávila, C. J., \& Parra, J. R. P. (2002). Desenvolvimento de Diabrotica speciosa (Germar) (Coleoptera: Chrysomelidae) em diferentes hospedeiros. Ciência Rural, 32, 739-743. https://doi.org/10.1590/S010384782002000500001

Ávila, C. J., \& Parra, J. R. P. (2003). Leaf consumption by Diabrotica speciosa (Coleoptera: Chrysomelidae) adults on different host plants. Science Agricola, 60, 789-792. https://doi.org/10.1590/S0103-901620 03000400028 
Ávila, C. J., \& Santana, A. G. (2013). Diabrotica speciosa: An importante soil pest in South America. In E. J. Pena (Ed.), Pontential invasive pests of agricultural crops (p. 440). CABI Series: CABI Invasive Species Series 3.

Awmack, C. S., \& Leather, S. R. (2002). Host plant and fecundity in herbivorous insects. Annual Review of Entomology, 47, 817-844. https://doi.org/10.1146/annurev.ento.47.091201.145300

Boiça Júnior, A. L., Costa, E. N., de Souza, B. H. S., Ribeiro, Z. A., \& Carbonell, S. A. M. (2015). Antixenosis and Tolerance to Diabrotica speciosa (Coleoptera: Chrysomelidae) in Common Bean Cultivars. Florida Entomologist, 98, 464-472. https://doi.org/10.1653/024.098.0212

Branson, T. F., \& Krysan, J. L. (1981). Feeding and oviposition behavior and life-cycle strategies of Diabrotica: An evolutionary view with implications for pest management. Environmental Entomology, 1, 826-831. https://doi.org/10.1093/ee/10.6.826

Cabrera Walsh, G., \& Cabrera, N. (2016). Biogeografia de Diabrotica lato sensu Neotropicais. In D. E. Nava, C. J. Ávila, \& A. S. Pinto (Eds.), Diabrotica speciosa (p. 200). Ocasio, Brasil.

Cabrera Walsh, G. (2003). Host range and reproductive traits of Diabrotica speciosa (Germar) and Diabrotica viridula (F.) (Coleoptera: Chrysomelidae), two species of South American pest rootworms, with notes on other species of Diabroticina. Environmental Entomology, 32, 276-285. https://doi.org/10.1603/0046-225X $-32.2 .276$

Cohen, A. C. (2015). Insect diets: science and technology (pp. 1-164). Boca Raton: CRC Press. https://doi.org/ $10.1201 / \mathrm{b} 18562$

Costa, E. N., Nogueira, L., de Souza, B. H. S., Ribeiro, Z. A., Louvandini, H., Zukoff, S. N., \& Júnior, A. L. B. (2018). Characterization of Antibiosis to Diabrotica speciosa (Coleoptera: Chrysomelidae) in Brazilian Maize Landraces. Journal of Economic Entomology, 9, 454-462. https://doi.org/10.1093/jee/tox350

Costa, E. N., Ribeiro, Z. A., de Souza, B. H. S., \& Boiça Júnior, A. L. (2014). Oviposition preference assessment of Diabrotica speciosa (Coleoptera: Chrysomelidae) for different soybean genotypes. Intern. Pest Management Science, 6, 52-58. https://doi.org/10.1080/09670874.2014.900586

De Carli, M., Recha, C., Bento, J. M. S., \& Nardia, C. (2018). Sexual dimorphism in Diabrotica speciosa and Diabrotica viridula (Coleoptera: Chrysomelidae). Revista Brasileira de Entomologia, 62, 172-175. https://doi.org/10.1016/j.rbe.2018.04.004

Eben, A., \& Monteros, A. E. (2013). Tempo and mode of evolutionary radiation in Diabroticina beetles (genera Acalymma, Cerotoma, and Diabrotica). ZooKeys, 332, 207-231. https://doi.org/10.3897/zookeys.332.5220

Garcia, A., Cônsoli, F. L., Godoy, W. A. C., \& Ferreira, C. P. (2014). A mathematical approach to simulate spatio-temporal pattern of an insect-pest, the corn rootworm Diabrotica speciosa (Coleoptera: Chrysomelidae) in intercropping systems. Landscape Ecologia, 29, 1531-1540. https://oi.org/10.1007/ s10980-014-0073-4

Johnson, S. N., \& Gregory, P. J. (2006). Chemically mediated host-plant location and selection by root-feeding insects. Physiological Entomology, 31, 1-13. https://doi.org/10.1111/j.1365-3032.2005.00487.x

Lara, F. M., Scaranello, A. L., Baldin, E. L. L., Boiça Júnior, A. L., \& Lourenção, A. L. (2004). Resistência de genótipos de batata de larvas e adultos de Diabrotica speciosa. Horticultura Brasileira, 22, 761-765. https://doi.org/10.1590/S0102-05362004000400019

Marchioroa, C. A., \& Krechemer, F. S. (2018). Potential global distribution of Diabrotica species and the risks for agricultural production. Pest Management Science, 74, 2100-2109. https://doi.org/10.1002/ps.4906

Marques, G. B. C., Ávila, C. J., \& Parra, J. R. P. (1999). Danos Causados por larvas e adultos de Diabrotica speciosa (Coleoptera: Chrysomelidae) em milho. Pesquisa Agropecuária Brasileira, 34, 1983-1986. https://doi.org/10.1590/S0100-204X1999001100002

Milanez, J. M., \& Parra, R. P. J. (2000). Preferência de Diabrotica speciosa (Germar) (Coleoptera: Chrysomelidae) para oviposição em diferentes tipos e umidade de solos. Anais da Sociedade Entomologica Brasileira, 29, 155-158. https://doi.org/10.1590/S0301-80592000000100019

Naranjo, S. E., \& Sawyer, A. J. (1987). Reproductive biology and survival of Diabrotica barberi (Coleoptera: Chrysomelidae): Effect of temperature, food, and seasonal time of emergence. Annals of the Entomological Society of America, 80, 841-848. https://doi.org/10.1093/aesa/80.6.841 
Oliveira, B. M., \& Ramos, V. M. (2012). Simulação de dano de Diabrotica em feijoeiro (Phaseolus vulgaris) para estimativa de nível de ação. Revista Agrarian, 5, 181-186.

Panizzi, A. R., \& Parra, J. R. P. (2009). A bioecologia e nutrição de insetos como base para o manejo integrado de pragas. In A. R. Panizzi, \& J. R. P. Parra (Eds.), Bioecologia e nutrição de insetos: Base para o manejo integrado de pragas (pp. 1107-1140). Brasília, Embrapa/CNPq.

Parra, J. R. P. (2001). Técnicas de criação de insetos para programas de controle biológico (p. 134). Piracicaba: ESALQ.

Pecchioni, M. T. D., Cabrera, N., Laguzzi, S. M., \& Novara, C. R. (2000). Aspectos morfológicos y problacionales de Diabrotica speciosa speciosa (Germar) (Coleoptera: Chrysomelidae) en condiciones de laboratorio. Anais da Sociedade Entomologica Brasileira, 29, 285-294. https://doi.org/10.1590/S030180592000000200010

Pereira, T., Ventura, M. U., \& Marques, F. A. (2005). Comportamento de larvas de Diabrotica speciosa (Coleoptera: Chrysomelidae) em resposta ao $\mathrm{CO}_{2}$ e as plântulas de espécies cultivadas. Ciência Rural, 35, 981-985. https://doi.org/10.1590/S0103-84782005000500001

Rasmann, S., Köllen, T. G., Degenhard, J., Hiltpold, I., Toepfer, S., Kuhlmann, U., Gershenzon, J., \& Turlings, T. C. J. (2005). Recruitment of entomopathogenic nematodes by insect damaged maize roots. Nature, 434, 732-737. https://doi.org/10.1038/nature03451

Rasmann, S., \& Turlings, T. C. J. (2008). Simultaneous feeding by aboveground and below ground herbivores attenuates plant-mediated attraction of their respective natural enemies. Ecology Letters, 10, 926-936. https://doi.org/10.1111/j.1461-0248.2007.01084.x

Santos, F., Penãflor, M. F. G. V., Pare, P. W., Sanches, P. A., \& Kamiya, A. C. (2014). A Novel Interaction between Plant-Beneficial Rhizobacteria and Roots: Colonization Induces Corn Resistance against the Root Herbivore Diabrotica speciosa. PLoS ONE, 9, e113280. https://doi.org/10.1371/journal.pone.0113280

Teodoro, J. S., Martins, J. F. S., Rosa, A. P. S. A., Castro, C. M., \& Cunha, U. S. (2014). Characterization of potato genotypes for resistance to Diabrotica speciosa. Horticultura Brasileira, 32, 1-6. https://doi.org/ $10.1590 / \mathrm{S} 0102-053620140000400011$

Ventura, M. U., Mello, E. P., Oliveira, A. R. M., Simonelli, F., Marques, F. A., \& Zarbin, P. H. G. (2001). Machos são atraídos por armadilhas com fêmeas: Uma nova perspectiva para manejo de Diabrotica speciosa (Germar) (Coleoptera: Chrysomelidae) usando feromônio sexual. Neotropical Entomology, 30, 361-364. https://doi.org/10.1590/S1519-566X2001000300003

Ventura, M. V., \& Gomes, M. R. (2004). Population study of Diabrotica speciosa (Ger.) (Coleoptera: Chrysomelidae) in fall/winter season. Ciência Rural, 34, 1939-1943. https://doi.org/10.1590/S0103-84782 004000600042

\section{Copyrights}

Copyright for this article is retained by the author(s), with first publication rights granted to the journal.

This is an open-access article distributed under the terms and conditions of the Creative Commons Attribution license (http://creativecommons.org/licenses/by/4.0/). 